\title{
Using a Personal Portfolio for Identity Development with an Adolescent
}

\author{
Suzanne Bester \\ Mugsy Quinn \\ University of Pretoria, South Africa
}

Address correspondence to Doctor Suzanne Bester, Faculty of Education, University of Pretoria, 0002, Pretoria, South Africa. E-mail: suzanne.bester@up.ac.za

This article reports on the findings of an instrumental case study that was exploratory and descriptive in nature. An open and flexible investigation was conducted with the purpose of gaining insight into the potential value of using a personal portfolio to facilitate an adolescent's quest for identity development. The focus was on how a personal portfolio could facilitate the narration of the participant's life story and what the outcome was on self-understanding. Findings suggest that compiling a personal portfolio enabled an awareness of personal assets and an overall improved sense of self-worth and self-confidence.

Keywords: personal portfolio, adolescence, identity, identity development, identity crisis, self-exploration, post-modern approach, narratives, life story

Adolescents often ask existential questions during their transition from childhood to adulthood: Who am I? What is my place in society? Where am I going in life? What is my purpose on this earth? In addition to the physical, cognitive, social and personality changes that adolescents experience, they also engage in a quest for identity. Identity development, considered one of the hallmarks of adolescence, is an extremely complex construction that has multiple domains (Hill, Bromell, Tyson, \& Flynt, 2007). Constructing an identity involves defining who you are, what you value, and what direction you wish to pursue in life. Berk (2000) elaborates on this by claiming that the search for what is true, real, and indispensable to the self is the driving force behind many commitments, such as sexual orientation, a vocation, interpersonal relationships, community involvement, ethnic group membership, and moral, political, religious, and cultural ideals.

This article reports on the findings of an exploratory and descriptive study that aimed at gaining insight into the potential value of using a personal portfolio to facilitate an adolescent's quest for identity development. The particular focus of this exploration was on how a personal portfolio could facilitate the narration of the participant's life story and what the outcome was in regard to self-understanding.

There is no commonly agreed-upon definition of identity (Kail \& Cavanaugh, 2001; Thom \& Coetzee, 2004). Identity development is a complex, multifaceted concept, which embraces an array of social and self-representations, including personal, public, individual and group identities. For instance, identity formation in adolescence requires adolescents to explore a range of life choices about interpersonal and ideological domains before they make commitments (Graf, Mullis, \& Mullis, 2008). Identity achievement is a crucial step towards becoming a productive, happy adult, as it serves as a basis for adult expectations and goals (Berk, 2000). A negative outcome of adolescence is identity confusion, which results in the adolescent being unprepared for the psychological challenges of adulthood (Hill et al., 2007). If the psychosocial crisis of "Identity versus Identity Diffusion" is not resolved during adolescence, it can result in role confusion, where an adolescent is unable to integrate his various roles, and lacks the ability and self-confidence to make decisions (Louw \& Louw, 2007).

\section{Our Approach}

Post-modern narrative techniques were utilized to construct the participant's personal portfolio. These techniques were selected in order to facilitate the exploration of the participant's subjective experiences and to encourage self-exploration. Post-modernism emphasises the value of taking account of a multiplicity of perspectives, contextual influences, social construction of reality, as well as the subjective meaning that individuals ascribe to their own experiences (Maree, Ebersöhn \& Vermaak, 2008). It thus implies that the universe cannot be understood objectively and that reality exists in the assumptions of the observer (Maree, Ebersöhn, \& Molepo, 2006). This shift to subjectivism is especially relevant in multicultural, pluralistic countries like South Africa (Maxwell, 2007).

Narrative theory is a post-modern approach which assumes that the stories people tell of themselves unify their identities (Brooks \& Dallos, 2009). Individuals create internalised narratives or stories in the process of development (Winston, Rice, Bradshaw, Lloyd, Harris, Burford, Clodmir, Kizzie, Carothers, McClair, \& Burrell, 2004) and people live multi-storied lives with numerous narratives taking place at the same time, resulting in continuous negotiation and interpretation of their experiences (Morgan 2000). According to Cochran (1997) the aim of the narrative approach is to reveal a person's life story and the role it plays to enable the individual to understand his personal identity and facilitate the setting of priorities and values.

\section{Personal Portfolio}

The personal portfolio used in this study draws on the research findings of Jones (2009); Segers, Gijbels, and Thurlings (2008); Fernsten and Fernsten (2005); and Losardo and Notari-Syverson (2001), according to whom a portfolio usually includes different types of performance-based samples such as artwork, picture journals and dictation, as well as teacher and parent observations. No specific rules dictate the appearance of a portfolio. Portfolio assessment approaches share the basic 
tenets of ecological and social constructivist views of child development, which emphasise performance-based assessments that provide a complex, comprehensive and meaningful portrait of the child. Portfolios are flexible and open-ended and content is chosen according to the individual's needs. The construction of a portfolio promotes deep learning, which is associated with searching for meaning and is driven by an intrinsic motivation to seek meaning and understanding. It is further reported that engagement in portfolio activities can trigger reflection that is not often present in everyday practice.

This study set out to provide insight into the potential value of a personal portfolio as a means to facilitate an adolescent's quest for identity development. The focus was on how a personal portfolio could facilitate the adolescent's narration of his life story and the concomitant effect on self understanding. The study was guided by the following research questions: What is the potential value of a personal portfolio for identity development of an adolescent? How did the adolescent experience completing the personal portfolio? How can post-modern narrative techniques be applied in the process of identity exploration and construction?

\section{Method}

\section{Participant and Setting}

One participant was identified and selected using purposeful convenience sampling from a high school in the northern province of South Africa. The participant was selected according to a set of criteria that included the following: (a) adolescent; (b) accessible and available; and (c) able to reflect on the research process and express his feelings.

Research took place in a private (neutral) setting (an office on the school premises). The participant was removed from the school group setting during official school period. Sessions took place when the participant had a free period or after school hours.

\section{Design}

An instrumental case study was used to obtain a rich description of how the research participant experienced compiling a personal portfolio and the extent to which a personal portfolio supported his identity development. Mouton (2001) points out that the main strengths of a case study design include its high construct validity and the opportunities it offers to arrive at in-depth insights, as well as to establish good rapport with research participants. These, together with the flexibility and openness of the design, allowed us to address any unexpected issues as they arose during the research process, as well as to "catch the close-up reality and thick description of participant's lived experiences of, thoughts about and feelings for, a situation" (Cohen, Manion \& Morrison, 2002, p. 182).

The various portfolio activities utilised in this study were chosen to facilitate the active engagement of the adolescent in meaningful activities, which could enable the narration of a comprehensive life story. The activities were chosen with the adolescent stage of development in mind and were participant-orientated, which enabled the adolescent to complete the activities in any way with which he felt comfortable. The goal of the activities was to provide the participant with the opportunity for deeper introspection and to allow the participant to reflect on both the process and value of each activity, as well as on the personal portfolio as a whole. The aim with this process was to promote communication between the participant and the researcher through the personal portfolio activities.

In the light of Durrheim and Wassenaar's (2002) claim that qualitative research findings can never be a true reflection of reality, we adopted certain strategies to ensure credibility and trustworthiness in this study.

\section{Data Collection Procedures}

To establish credibility the researchers employed triangulation (different types of evidence were collected), prolonged engagement in the field $(10 \times 60$ minute sessions were carried out over eight weeks) and persistent observations (continuous observations of the participant were carried out and recorded in a research diary). Participant-checking was also carried out after initial data analysis to ensure that the research results were an accurate portrayal of the participant's experiences and perceptions.

The challenge of implementing a case study design may include the lack of generalisability of results, establishing the validity of information, difficulty in testing causal links, non-standardisation of measurement and time-consuming analysis (Lindegger, 2002). Furthermore, Mouton (2001) identifies researcher bias and lack of rigour in analysis as other possible shortcomings in case study research.

Dependability of the data was achieved by leaving an audit trail, documenting the data, methods and decisions made during the study. The chain of evidence provided by the audit trail, as well as the reflexive methodological account in a research diary were methods used to establish confirmability, while detailed descriptions and reflections of each session were documented in a research diary which could provide sufficient information to judge the applicability of the findings to other settings.

\section{Data Collection Methods}

According to Cohen et al. (2002) participant observation, interviews, narrative accounts, documents, and diaries are data collection methods used in interpretative paradigm case studies. To ensure that rich and detailed data were collected the researcher used multiple sources of evidence. The following methods of data collection were used:

Personal portfolio activities. The research participant was engaged in completing the following activities:

- Drawing (1): the participant was instructed to draw a picture or symbol entitled What I am.

- Individual identity collage: the collage consisted of two stages. The first stage involved the participant reflecting on questions such as: Who am I? What are my goals? What is important to me? What do I enjoy? What is my dream? What would I like to do? Who are my role models? The second stage involved the participant creating a collage using pictures, words, quotes and/or drawings.

- Interests, talents and values: this activity required the participant to reflect on what his interests, talents and values were and to represent these visually.

- Life line (Cochran, 1997): a line was drawn across the midpoint of a blank piece of paper. On the far left the beginning of the line was labelled "birth". The participant was asked to recall milestone experiences in his life and to record them chronologically. In this activity, experiences are recorded by placing a dot higher on the sheet to the extent that it is posi- 
tive or lower on the sheet to the extent that it is negative. Each dot is labelled to identify the event and then the dots are connected to represent the flow of the client's life graphically.

- My circle of influences: this activity required the participant to identify and reflect on the people who had influenced his life in both positive and negative ways. The participant was then asked to plot these influences around a circle that represented them. The closer to the circle the greater the influence.

- Life chapters (Cochran, 1997): the participant was asked to think of his life as an autobiography. The chapter titles needed to reflect or sum up a particular period in his life. The participant was asked to write a few lines elaborating on each chapter title.

- Success and failure experiences (Cochran, 1997): the participant was asked to think about and write about three past success and failure experiences.

- Job from heaven, job from hell: this activity required the client to describe, in detail, two different work days. What he would consider as a perfect day at work and a nightmarish day at work.

- Drawing (2): after reflecting on the entire personal portfolio the participant was again asked to draw a picture or symbol entitled: What I am.

Open-ended interviews. After each session the research participant was asked to reflect on the completed activity, both orally and in writing. The researcher facilitated the reflection process by issuing instructions or asking open-ended questions such as:

- Tell me about the activity you have just completed.

- What were you thinking while you were completing the activity?

- What feelings were you experiencing while you were completing the activity?

- How did you experience completing the activity?

- The open-ended interviews were tape-recorded and transcribed.

Reflective reports. The research participant was given a diary and at the end of each session was asked to take the activity home and to once again reflect on it in his diary.

Research diary. The researcher kept a research diary throughout the research process. Both process and content notes were recorded. The diary was used to observe and record the participant's verbal and non-verbal responses during the interview as well as research and personal reflections.

\section{Data Analysis and Interpretation}

Data were analysed within a constuctivist-interpretivist framework by applying thematic analysis (Henning, Van Rensburg, \& Smit, 2004). The researcher used various reasoning strategies including inductive reasoning, analysis, synthesis and intuition to extract themes from the data (Poggenpoel, 1998). Emergent themes were delineated from the content. Most frequent themes were clustered into core categories, which were identified and interpreted utilising theoretical resources.
A follow-up interview with the research participant involved presenting the preliminary data analysis for member-checking. Participant comments were integrated into the findings.

\section{Findings and Discussion}

The data were divided into five core categories namely: Identity Crisis/Confusion, Identity Exploration, Identifying Developmental Assets, Unresolved Past Issues, and the Experience of Compiling a Personal Portfolio. These core categories were further linked to sub-categories and related themes, which will be discussed with reference to the literature surveyed.

\section{Identity Crisis/Confusion}

The first category correlates with Erikson's theory (1977), which states that adolescents are involved in a process of establishing an identity, which can be both challenging and confusing. Questioning overall personal identity and sexual identity conflict were identified as the two major sub-categories.

Questioning overall personal identity as a sub-category emerged during the first two sessions where the research participant expressed his sense of feeling 'lost' and not sure where he belonged.

- I cannot find myself.

- I still have the feeling that, where do I really belong?

Sexual identity conflict as a sub-category was evident during most of the process. The research participant expressed his uncertainty and confusion in statements such as:

- . . . manhunt and dating made me feel a little scared because every time I come to the word dating it drives me crazy because I ask do I really want to date and who do I want to date?

- At the end of the day I know that I want to be with someone but I'm confused about who?

The research participant initially revealed that he questioned his overall personal identity and was especially uncertain and confused about his sexual identity. These findings suggest that adolescents may require additional support during their quest for identity (Kail \& Cavanaugh, 2001).

\section{Identity Exploration}

The category of identity exploration is concerned with the quest to define who one is, what one values and what directions one wishes to pursue in life (Berk, 2000). While identity is multidimensional and may include many types of identity, future career and sexual identity were identified as the two major types of identity that the research participant was most concerned to explore.

The participant was concerned with further exploring his goals, beliefs and values with regard to his future career during many of the activities of the personal portfolio. These are important components to consider when establishing a career identity and deciding on a future career path.

Goals. The participant became aware of and was able to identify both short-term and long-term goals. He stated that he realised the importance of school and needed to work harder in order to achieve his long term goals of being successful, rich, and possibly owning his own company one day.

- I drew some books because I know education is important for me to get where I want in life. 
- Mrs Parr was strict. She showed me the love of cooking leadership and that hard work leads to success.

- I would love to open my own company and help those who need help.

Beliefs. The participant believed that he had a positive attitude towards life. He believed in his abilities and he saw himself as a 'people-person', a good speaker, a good problem solver, and able to motivate others and give them advice.

- But I learnt to be more open and to think positive even though things are tough.

- I try to be positive, and this gives me strength.

- I enjoy being around people, those who love being around me.

- My talents are talking a lot and making a deal with the right people, I can be a good speaker and I am good at motivating people and give people advices.

Values. The participant often referred to financial prosperity and success, helping the community, the importance of family and friends and happiness in life, when discussing different activities and in his reflections.

- I also want to be rich and inspire other people.

- I want to have money and help the community.

- I also realised that people are important in my life.

- My happiness comes first in life.

- ... happiness is important to me.

In order to develop a sexual identity one must also be aware of one's goals, beliefs and values with regard to one's sexual orientation and be able to commit one-self to those goals, beliefs and values. While the research participant was able to explore these components of his sexual identity, there was initially evidence of conflict or confusion. Further exploration and narration by the participant revealed the following:

Goals. The participant often stated that he was searching for 'the perfect partner'. He was well aware of the qualities he was looking for in a partner and what he wanted from a relationship.

- Manhunt is what I do, I search for men. I want a partner who will understand who I am, a person who is trustworthy and who is serious about life.

- Like I said before, I know I want to share my life with a partner but then I just don't know who. Who can I trust and who will give me what I need?

Beliefs. While the participant stated on different occasions that he was a homosexual male, he seemed to be experiencing some inner conflict or confusion. During participant-checking it emerged that the initial confusion and conflict he seemed to be conveying to the researcher were partially attributed to sexual identity conflict based on the fear of being judged by others, including the researcher. The final interview revealed a firm belief in his sexual preference and identity.

- I used to be like so ok I am a gay guy but then I look at my history and how I have been hurt in the past and I get confused. I think people will judge me but I think that this is what I really want.

- I wrote men and love two times because I am a gay guy and I am searching for love.
Values. The themes that emerged that were relevant to his sexual identity were his search for acceptance as a homosexual individual and the value he placed on a loving and committed relationship:

- My values: Being myself as a gay guy.

- I woke up at 7am next to my partner and we were kissing.

- I want a partner who is trustworthy and who is serious about life and I want a relationship that is challenging and someone who is really committed to our relationship.

Exploration is a precondition to establishing an identity (Kail \& Cavanaugh, 2001). Although the research participant was presented with a number of activities to facilitate his narration, his life story focused mainly on exploring his future career and his sexual identity. This confirms that an adolescent does not necessarily experience identity confusion in every type of identity. It is, however, important to note that the different types of identity contribute to overall personal identity.

The themes that emerged from his life story enabled the research participant to identify recurring themes and scripts with regard to his goals, beliefs and values. Identifying and evaluating one's goals, beliefs and values is one of the first steps in establishing an identity (Waterman, 2004).

Identifying assets. Discovering or becoming aware of one's strengths and assets ties in with the post-modern narrative approach that was used in compiling the personal portfolio. Identifying and mobilising one's strengths and resources can serve as protective factors which may be filled with challenges and inner conflict. The research participant revealed a number of internal and external assets in his personal portfolio activities and during interviews and discussions.

External assets. The participant often spoke about external assets such as a supportive family and supportive friends, his community orientation, adult role models and high expectations placed on him by family and friends.

- My sister taught me how to really trust myself and to believe in myself. She always said that I can do anything I want and I believed her

- I think that some people will judge me but I think that this is what I really, really want and am comfortable with, I know that my true friends will accept and support me.

- I want to live a good life and help my family and community.

- Oprah is someone I look up to. She achieved a lot in life and I also want to be rich and inspire other people

Internal assets. As the activities progressed, the research participant's narration identified internal assets such as being achievement motivated and having a positive view of his personal future. His writing also reflected his belief that he possessed interpersonal competence and positive values such as being caring and striving for equality and social justice.

- I thought about what those people have achieved in their lives and how I also can achieve those things and maybe make them a little bigger that theirs.

- I try to be positive about things and value my happiness.

- The river is how I think my friends see me - a strong, positive friend. They rely on me a lot and believe in me a lot.

- I want to be able to help my mother and family one day. I also wish I could do something to help my community. 
Narrative therapy assumes that people have many competencies, beliefs, values and abilities which can assist them in reducing the influence of problems or challenges that they will encounter in their lives (Morgan, 2000). The post-modern narrative approach corresponds with positive psychology, of which asset based theory forms a part, in that it aims at uncovering a client's hidden strengths and resources.

The personal portfolio assisted the research participant to become aware of both his external and internal assets. Becoming aware of and mobilising these assets can help the adolescent cope better with challenges during adolescence and in the future. The research participant realised that he possessed developmental assets such as a supportive family and friends, a positive view of his personal future, interpersonal competencies and could identify with good adult role models. Mobilising these assets could help him with the difficulties he was experiencing in terms of his sexual identity and which future direction he wanted to pursue.

Unresolved past issues. A theme that emerged during the research process was that of an unresolved past issue. This theme is related to Erikson's (1977) view that an unresolved psychosocial crisis may hinder an adolescent from advancing to the next stage of psychosocial development. We believe that an unresolved past issue hampers an individual's ability to move forward with his life, especially with regard to setting future goals, establishing satisfying relationships and overall psychological well being.

Awareness of an unresolved past issue. In the first session of the research process the research participant became aware of an existing unresolved issue and this issue kept resurfacing.

- I want to heal myself.

- The red and orange clouds are the anger in me.

- I found it sad to think about those things, especially about the year that I was in Pretoria with my uncle.

Awareness of the impact on his life. After the unresolved past issue had surfaced on several occasions, the research participant seemed to become aware of the impact that it was having on his life.

- I sometimes try to run away from the bad things that have happened in my life.

- When I was doing the abused chapter, I was feeling angry and sad at the same time and I realised how maybe ignoring things doesn't help.

Resolution. At the end of the research process the research participant seemed to be more resolved.

- . . . now when I talk about it I don't get so angry and know that I can be positive and try to move on.

- The black mud is gone because I have let go of my past. I think that holding onto it and trying to shut it down made me sometimes not see the other side of life. But looking at things like my time line, my circle of influences and my life book made me realise that I can let go and move forward. The angry clouds are also gone.

- Ya, I think I've gained I could say facing my history that I tried to shut down and forget about. I had to face it and realise that it has somehow become part of me and makes me want to be better.
Cattanach (2002) believed that a person's stories are not mere stories, but a reflection of what has happened in their lives, or what they have experienced both consciously and unconsciously. The activities that the participant was required to complete resulted in the resurfacing of an unresolved past issue. Looking for recurring themes in his personal portfolio made the participant aware of this issue and its influence on his life. This research study did not involve therapeutic intervention, however. As would be the case in narrative therapy, the researcher allowed the participant to talk through his problems, and as is often the case, to find his own solution (Morgan, 2000).

Experience of compiling the personal portfolio. This theme is concerned with how the participant experienced the compilation of the personal portfolio for which the activities were aimed at initiating a process of self-exploration, and which included some that focused on the past, present and future, in order to elicit a comprehensive life story.

The research participant generally viewed the personal portfolio activities in a positive light and he was very proud of his final product. He described the activities as enjoyable, reporting that the process gave him new insights into himself (especially his strengths), since it helped him to achieve deeper levels of introspection and critical self-examination. It also helped him set future goals.

- I really had fun with my day in heaven.

- Yes I did because it helped me think about things that I didn't think about before and sort of find myself as well as see how some things work in my life.

- Mhh ... I had to really think hard and look back into my past and think about the people who influenced my life because I haven't really thought about this before.

- The sun is now smiling because many things happened during this process to help me set goals and made me realise that I have the confidence and can reach my dreams one day.

- I am so proud of what is in this file, I would like to do more of these activities.

The activities for the personal portfolio were selected with an adolescent's needs and competencies in mind. The stage of adolescence is not only a time for identity exploration and establishment (Erikson, 1977), but is also described by Berk (2000) as a second stage of egocentrism during which the individual is capable of abstract and self-reflective thought.

\section{Limitations of this Study}

- The following were discovered to be limitations and challenges during the research process:

- The in-depth case study involving just one research participant limits the generalisability of the research results.

- The themes that emerged were not verified by inter-rater verification.

- The research participant may have felt compelled to state positive feelings about the personal portfolio in order not to 'hurt the feelings' of the researcher. Since he knew that his answers were being audio recorded, his positive responses could have been the result of the Hawthorne effect (McMillan \& Schumacher, 2001). 
- Taking on the sole role of researcher was a challenge as narrative therapy involves more than simply listening to the stories that people tell. Effort was required not to step back into a therapist role, especially when sensitive issues arose.

- While the focus was on facilitating a research process in which the research participant could tell his life story with the aid of different activities, a possible language barrier could have resulted in the participant misunderstanding some of the instructions as well as being unable to express himself verbally, especially during feedback interviews.

\section{Conclusion}

This study aimed to obtain an in-depth understanding of the possible value of a personal portfolio as a method in supporting an adolescent's quest for identity development. The personal portfolio enables identity exploration in several domains: abilities and competencies, desires, relationships, interests, achievements and failures. Using a personal portfolio can be a cost-effective strategy to enable an adolescent to identify and clarify areas of identity confusion and personal goals, beliefs and values for important life decisions.

\section{References}

Berk, L. E. (2000). Child Development (5th ed.). Boston, MA Allyn and Bacon.

Brooks, E., \& Dallos, R. (2009). Exploring young women's understandings of the development of difficulties: A narrative biographical analysis. Clinical Child Psychology and Psychiatry, 14, 101-115.

Cattanach, A. (2002). The story so far: Play therapy narrative. London, England: Jessica Kingsley.

Cohen, L., Manion, L., \& Morrison, K. (2002). Research methods in education. London, England: Routledge Falmer.

Cochran, L. (1997). Career counselling: A narrative approach. Thousand Oaks, CA: Sage.

Durrheim, K., \& Wassenaar, D. (2002). Putting design into practice: Writing and evaluating research proposals. In M. Terre Blanche \& K. Durrheim (Eds.), Research in practice. Cape Town, South Africa: University of Cape Town Press.

Erickson, E. H. (1977). Childhood and society. New York, NY: Norton.

Fernsten, L., \& Fernsten, J. (2005). Portfolio assessment and reflection: Enhancing learning through effective practice. Reflective Practice, 6(2), 303-309.

Graf, S. C., Mullis, R. L., \& Mullis, A. K. (2008). Identity formation of United States American and Asian Indian adolescents. Adolescence, 43(169), 57-69.

Henning, E., Van Rensburg, W., \& Smit, B. (2004). Finding your way in qualitative research. Pretoria, South Africa: Van Schaik.

Hill, N. E., Bromell, L., Tyson, D. F., \& Flynt, R. (2007). Developmental commentary: Ecological perspectives on parental influences during adolescence. Journal of Clinical Child and Adolescent Psychology, 36(3), 367-377.

Jones, E. (2009). Personal theory and reflection in a professional practice portfolio. Assessment \& Evaluation in Higher Education, 1-12.

Kail, R. V., \& Cavanaugh, J. C. (2001). Human development: A lifespan view (2nd ed.). Belmont, CA: Wadsworth.
Lindegger, G. (2002). Research methods in clinical research. In M. Terre Blanche \& K. Durrheim (Eds.), Research in practice. Cape Town, South Africa: University of Cape Town Press.

Losardo. A., \& Notari-Syverson, A. (2001). Alternative approaches to assessing young children. Baltimore, MD: Paul. H. Brookes.

Louw, D., \& Louw, A. (2007). Child and adolescent development. Bloemfontein, South Africa: University of the Free State.

Maree, K., Ebersöhn, L., \& Molepo, M. (2006). Administering narrative career counselling in a diverse setting: trimming the sails to the wind. South African Journal of Education, 26(1), 49-60.

Maree, K., Ebersöhn, L., \& Vermaak, B. (2008). Confronting the effects of unemployment on achievement motivation: The case for postmodern career facilitation. Perspectives in Education, 26(3), 55-68.

Maxwell, M. (2007). Career counselling is personal counselling: A constructionist approach to nurturing the development of gifted female adolescents. Career Development Quarterly, 55(3), 206-225.

McMillan, J. H., \& Schumacher, S. (2001). Research in education. New York, NY: Addison-Wesley.

Morgan, A. (2000). What is narrative therapy? An easy-to-read introduction. Adelaide, South Australia: Dulwich Centre.

Mouton, J. (2001). How to succeed in your master's and doctoral studies: A South African guide and resource book. Pretoria, South Africa: Van Schaik.

Poggenpoel, M. (1998). Data analysis in qualitative research. In A. S. De Vos (Ed.). Research at grassroots: A primer for the caring professions. Pretoria, South Africa: Van Schaik.

Segers, M., Gijbels, D. \& Thurlings, M. (2008). The relationship between students' perceptions of portfolio assessment practice and their approaches to learning. Educational Studies, 34(1), 35-44.

Thom, D. P., \& Coetzee, C. H. (2004). Identity development of South African adolescents in a democratic society. Society in Transition, 35(1), 183-193.

Waterman, A. S. (2004). Finding someone to be: Studies on the role of intrinsic motivation in identity formation. Identity: An International Journal of Theory and Research, 4(3), 209-228.

Winston, C. E., Rice, D. W., Bradshaw, B. J., Lloyd, D., Harris, L. T., Burford, T. I., .. B Burrell, J. (2004). Science success, narrative theories of personality, and race self complexity: Is race represented in the identity construction of African American adolescents? New Direction for Child and Adolescent Development, 106, 55-77. 